\title{
Behavior-Dependent States of the Hippocampal Network Affect Functional Clustering of Neurons
}

\author{
Hajime Hirase, Xavier Leinekugel, Jozsef Csicsvari, András Czurkó, and György Buzsáki \\ Center for Molecular and Behavioral Neuroscience, Rutgers, The State University of New Jersey, Newark, \\ New Jersey 07102
}

Local versus distant coherence of hippocampal CA1 pyramidal cells was investigated in the behaving rat. Temporal crosscorrelation of pyramidal cells revealed a significantly stronger relationship among local $(<140 \mu \mathrm{m})$ pyramidal neurons compared with distant $(>300 \mu \mathrm{m})$ neurons during non-thetaassociated immobility and sleep but not during thetaassociated running and walking. In contrast, cross-correlation between local pyramidal cell-interneuron pairs was significantly stronger than between distant pairs during theta oscillations but were similar during non-theta-associated behaviors. We suggest that network state-dependent functional clustering of neuronal activity emerges because of the differential contribution of the main excitatory inputs, the perforant path, and Schaffer collaterals during theta and non-theta behaviors.

Key words: pyramidal cell; interneuron; sleep; synchrony; theta; sharp waves
Neighboring and distant hippocampal "place" cells have been postulated to have the same probability for representing the same part of the environment (O'Keefe and Nadel, 1978; Muller et al., 1987; Wilson and McNaughton, 1993), suggesting that, unlike neocortical structures, the hippocampus does not code information in a simple topographic format (but see Eichenbaum et al., 1989). In contrast, paradigms that involve other than place learning indicate that nearby hippocampal neurons may discharge together, suggesting local clustering of similarly responding neurons (Hampson et al., 1996; Thompson 1986, 1999).

Functional clustering of actively spiking neurons depends primarily on the configuration of the inputs. In various networks states, different sets of afferents may drive the same neuronal population, giving rise to state-dependent firing relationship among the cells. The two major network patterns of the hippocampus are theta oscillation in the awake, exploring rat and during REM sleep and non-theta state associated with consummatory behaviors and slow wave sleep (SWS) (Vanderwolf, 1969; Buzsáki et al., 1983; Bland, 1986; Stewart and Fox, 1990; Chrobak and Buzsáki, 1996). The entorhinal input and the Schaffer collateral afferents are the major pathways that are critically involved in the generation of theta oscillation and sharp waves of non-theta state in the CA1 region, respectively (Buzsáki et al., 1983). These pathways have different topographic distributions in the CA1 region (Amaral and Witter, 1989; Ishizuka et al., 1990; Li et al., 1994; Tamamaki and Nojyo, 1995). We hypothesized that the state-dependent participation of afferents may affect the spatial clustering of neuronal discharges in the hippocampal CA1 region.

\section{MATERIALS AND METHODS}

Twelve male rats of the Long-Evans strain (300-500 gm) were implanted with eight individually movable tetrodes. The tetrodes were inserted into

Received Dec. 18, 2000; revised Feb. 16, 2001; accepted March 2, 2001.

This work was supported by National Institutes of Health Grants NS34994 and MH54671, the Human Frontier Science Program (X.L.), the Uehara Memorial Foundation (H.H.), and the Kirby Foundation.

Correspondence should be addressed to György Buzsáki, Center for Molecular and Behavioral Neuroscience, Rutgers University, 197 University Avenue, Newark, NJ 07102. E-mail: buzsaki@axon.rutgers.edu.

Copyright (C) 2001 Society for Neuroscience 0270-6474/01/210001-04\$15.00/0 the CA1 pyramidal layer with $300 \mu \mathrm{m}$ center spacings. Before implantation, the rats were trained to run continuously in a running wheel (29.5 $\mathrm{cm}$ in diameter) for water reinforcement available in an adjacent box (Czurkó et al., 1999). After amplification $(10,000 \times)$ and band-pass filtering $(1 \mathrm{~Hz}$ to $5 \mathrm{kHz}$ ) field potentials and extracellular action potentials were digitized continuously at a $20 \mathrm{kHz}$ rate with a DataMax system (16-bit resolution; RC Electronics, Santa Barbara, CA). Interneurons and pyramidal cells were separated by a multidimensional clustering method using the principal components of the detected spikes (Wilson and McNaughton, 1993; Csicsvari et al., 1999). Only units with clear refractory periods, well defined cluster boundaries, and firing rates $>0.02 \mathrm{~Hz}$ were included in the analysis. Theta activity during the wheel running task was detected by calculating the ratio of the Fourier components of the theta $(5-10 \mathrm{~Hz})$ and delta $(2-4 \mathrm{~Hz})$ frequency bands. Non-theta epochs with sleep posture and closed eyes were classified as SWS. A ratio of more than six identified theta epochs and epochs with less than three theta/delta ratios identified non-theta epochs.

To quantify coactivation of neurons, first a cross-correlogram between cell pairs was computed. Each bar of the histogram was divided by the bin width and by the total length of recording. This normalized the cross-correlogram (i.e., when two units are not correlated, the height of the bar is equal to the product of firing rate[unit 1] and firing rate[unit 2]; in square Hertz). Next, the cross-correlogram was further divided by the firing rates of unit 1 and unit 2. This produced cross-correlograms that were independent of firing rate of the units. The summed center bins of the cross-correlograms $(100 \mathrm{msec})$ were used for examining the relationship between coactivity of local (i.e., neurons isolated from the same tetrode) versus distal (neurons recorded from different tetrodes) neuron pairs. After completion of the experiments, the rats were deeply anesthetized and perfused. The brains were sectioned and stained with the cresyl violet method to verify electrode placements.

This article is published in The Journal of Neuroscience, Rapid Communications Section, which publishes brief, peerreviewed papers online, not in print. Rapid Communications are posted online approximately one month earlier than they would appear if printed. They are listed in the Table of Contents of the next open issue of JNeurosci. Cite this article as: JNeurosci, 2001, 21:RC145 (1-4). The publication date is the date of posting online at www.jneurosci.org.

http://www.jneurosci.org/cgi/content/full/5223 


\section{Theta}

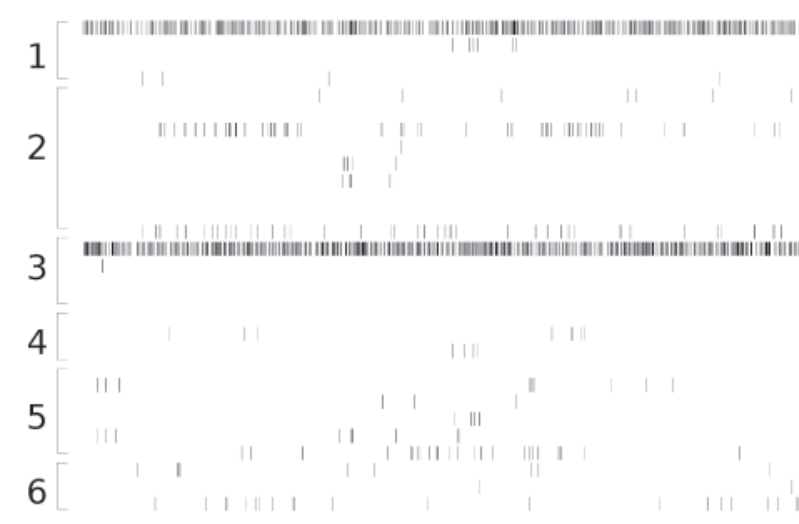

Non-theta

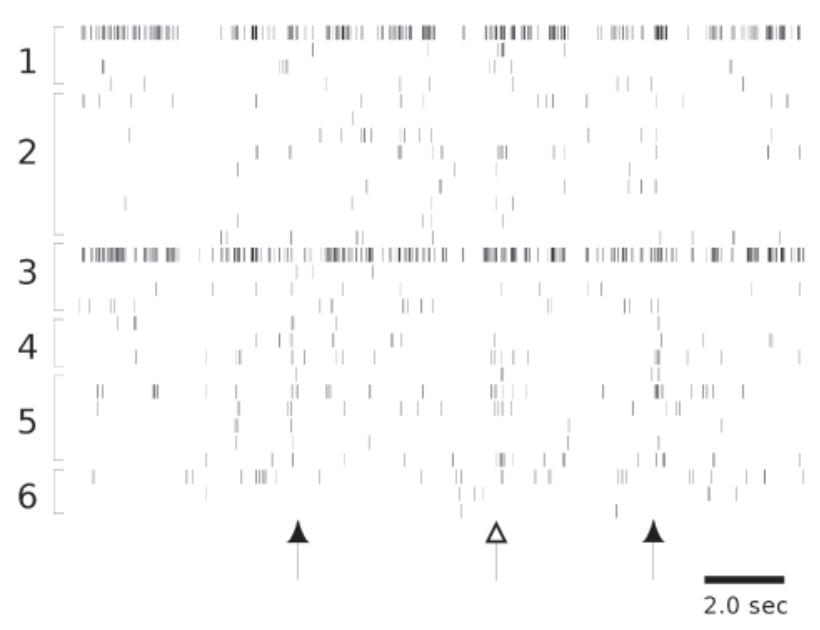

Figure 1. Population synchrony is state dependent. Simultaneous recording of pyramidal cells and interneurons (high frequency ticks in electrodes 1 and 3) from six tetrodes in theta and non-theta state. Vertical ticks indicate isolated units from different tetrodes. Note long alternating epochs of silence and discharge of pyramidal cells in theta state. Note also synchronous discharge of nearly all cells across tetrodes (open arrow) or more restricted synchrony to one or two tetrodes ( filled arrows).

\section{RESULTS}

Spike data were collected during two different network states of the hippocampus. Theta behaviors refer to running in the wheel and walking in the box area of the training apparatus. Non-theta behaviors included immobility and SWS recorded in the home cage of the rat (Fig. 1). The autocorrelograms of spike data were similar during running and walking and also during immobility and SWS. The data analysis is based on 140 pyramidal cells and 28 interneurons in 12 rats.

Local clustering of neuronal activity was examined by crosscorrelating cell discharges of neighboring $(<140 \mu \mathrm{m})$ and distant $(>300 \mu \mathrm{m})$ neurons. Local neurons, recorded from the same electrode, were $<140 \mu \mathrm{m}$ from each other because this is the maximum diameter of a cylinder of CA1 pyramidal neurons from which wire tetrodes can record spikes with sufficiently large amplitude to be discriminated (Henze et al., 2000).

Figure 2 summarizes the main findings. Interactions among local or distant pyramidal neurons were similar during theta state, as revealed by the similar correlations between neuron pairs recorded from the same or different tetrodes (Fig. 2a). The central peaks flanked by additional peaks in the crosscorrelogram at $\sim 130 \mathrm{msec}$ reflect theta modulation of pyramidal cells (Csicsvari et al., 1999). In contrast, local pyramidal neurons displayed a significantly stronger temporal correlation than distant pyramidal cells in non-theta state $(p<0.0005 ; t$ test) (Fig. $2 b$ ). In addition to the correlations among pyramidal cells, we also examined the correlations between pyramidal cells and simultaneously recorded interneurons (Fig. $2 c, d$ ). This comparison revealed a different spatial clustering. Similar to pyramidal cellpyramidal cell interactions, the correlations between locally recorded pyramidal cell-interneuron pairs were stronger than between distant pyramidal cells and interneurons. However, the local versus distal difference was significant only in theta state $(p<0.02)$ (Fig. 2c).

The duration of elevated coactivity was $\sim 100 \mathrm{msec}$ in all cross-correlograms, independent of the network state (Fig. 2). These peaks reflect time-locked discharges of pyramidal cells and interneurons to the same phase of the theta cycle during running and walking and coactivation of most neurons during intermittent sharp wave bursts of non-theta behaviors (Buzsáki et al., 1992; Csicsvari et al., 1999). Furthermore, the magnitude of the central peaks in the cross-correlograms was larger in non-theta states than in theta state, reflecting a significantly stronger population synchrony during sharp waves of non-theta state compared with theta oscillations (Buzsáki et al., 1992; Csicsvari et al., 1999).

\section{DISCUSSION}

The major findings of the present experiments are that the temporal correlation among neurons depends on the distance of the recorded neurons as well as on the state of the network. Furthermore, the state-dependent modulation of coactivation also depended on the neuron types. Our findings are compatible with previous suggestions that neighboring and distant place cells have the same probability of coactivation in the awake rat (O'Keefe and Nadel, 1978; Muller et al., 1987; Wilson and McNaughton, 1993; Redish et al., 2000) (but see Eichenbaum et al., 1989). However, the findings also show a high local coherence of pyramidal cell discharges during behaviors characterized by the absence of theta oscillations.

We suggest that the state-dependent relative activity of afferent pathways, mediating theta and non-theta network patterns, might explain the state-dependent differences in neuronal synchrony as a function of distance. Theta oscillations and sharp waves of non-theta states represent two extreme states of excitability in the hippocampal network. However, during natural behaviors, a variety of intermediate excitability patterns are present (Buzsáki et al., 1983). Theta waves emerge as a result of a complex interaction between the entorhinal input, the CA3 associational inputs, and rhythmically firing interneurons (Buzsáki et al., 1983). Both the associational and entorhinal inputs to CA1 neurons have well defined but distinct topographic distributions (Amaral and Witter, 1989; Ishizuka et al., 1990; Li et al., 1994). Differential activity of these inputs may give rise to a variety of functional maps in the CA1 neuronal population. On the other hand, non-theta state 


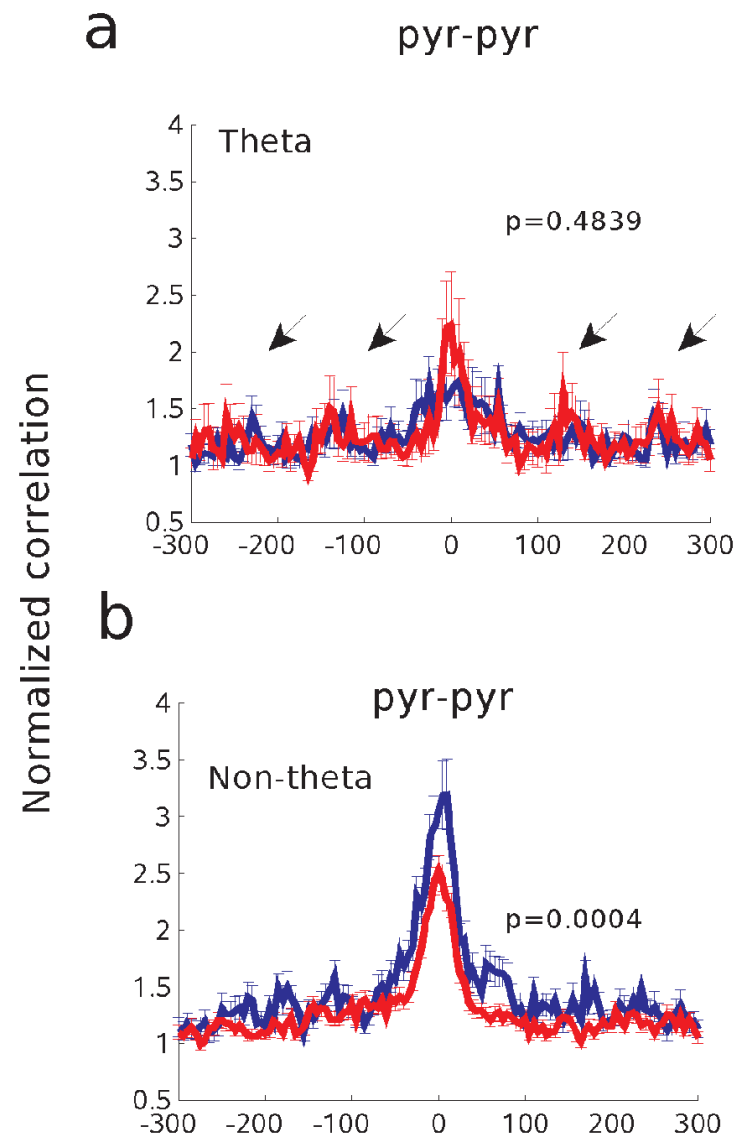

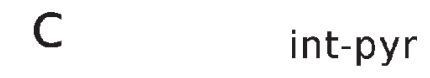
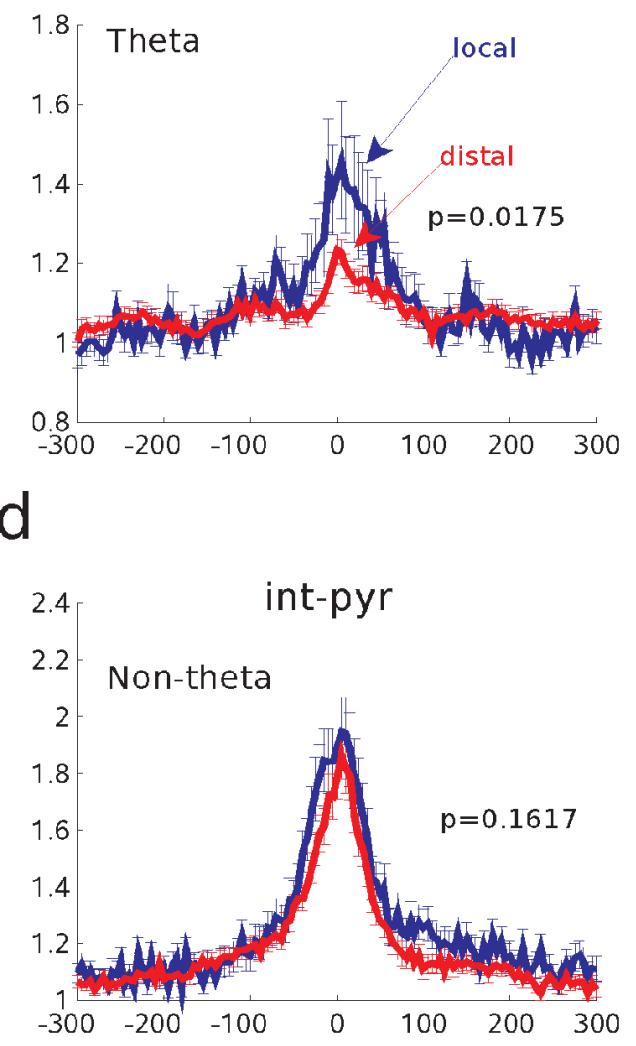

Time (ms)

Figure 2. The magnitude of temporal correlation among neurons depends on the state of the hippocampal network and the distance between the recorded neurons. Averaged cross-correlations between local ( $<140 \mu \mathrm{m} ;$ blue, within tetrode) and distant ( $>300 \mu \mathrm{m}$; red, across tetrode) CA1 pyramidal cells in theta state $(a)$ and non-theta state $(b)$. Arrows in $a$ indicate theta rhythmicity. Note stronger correlation between locally recorded pyramidal cells in non-theta state. $c, d$, Cross-correlations between pyramidal cells ( pyr) and interneurons (int). Note stronger correlation between neighboring pyramidal cells and interneurons (local) compared with distant pairs in theta state. Vertical bars indicate SE. Pyramidal-pyramidal cross-correlations are based on 182-433 pairs; pyramidal-interneuron cross-correlations are based on 33-84 pairs. $p$ values were calculated for the -50 to 50 msec epochs ( $t$ test).

characterized by intermittent sharp wave bursts reflect the activity of the CA3-CA1 connections (Buzsáki et al., 1983; Ylinen et al., 1995). Therefore, a simpler functional clustering of neurons is expected in non-theta state. In support of this hypothesis, activity of single CA3 pyramidal neurons can predict the location of sharp wave-associated ripple oscillations $(140-200 \mathrm{~Hz})$ in the CA1 pyramidal layer with better than $600 \mu \mathrm{m}$ spatial resolution (Csicsvari et al., 2000).

The significantly higher spike correlation of locally recorded pyramidal cell-interneuron pairs, compared with distant pairs during theta activity, can be explained by the network statedependent modulation of spike transmission probability between pyramidal cells and interneurons (Miles, 1990; Csicsvari et al., 1998; Verheugen et al., 1999). In those studies, most of the monosynaptically connected pyramidal cell-interneuron pairs were recorded within $<150 \mu \mathrm{m}$. Furthermore, the spike transmission probability between pyramidal cells and interneurons varied as a function of behavior and the firing pattern of the presynaptic pyramidal cell. The maximum spike transmission probability occurred at 5-25 Hz of pyramidal activity (Marshall et al., 2000), a range that is comparable with the activity of place cells (O'Keefe and Nadel, 1978). Overall, pyramidal-interneuron spike trans- mission probability is decreased during sharp wave bursts. Although both neuronal populations show marked increase in discharge rate, the rate of increase is much larger for pyramidal cells, resulting in a transient twofold to threefold gain in network excitability (Csicsvari et al., 1999). These observations suggest that the potentiating effects between pyramidal-interneuron pairs during theta activity may be responsible for the increased cross-correlation in theta state.

An implication of our observations is that, when the network state of the hippocampus varies in a given behavioral task, the temporal relationship of the recorded neurons will vary as a function of their distance. A recent paper reported behaviordependent anatomical clustering of hippocampal cell activity, implying that computation of various task variables were performed by anatomically segregated groups of neurons (Hampson et al., 1999). Figure $1 a$ of that paper shows that the ensemble discharge rate of the hippocampal network varied twofold to threefold within both the same behavioral trial and across correct and incorrect trials. The magnitude of within-trial firing rate changes at the population level was similar to the expected variation in network excitability along the theta-sharp wave continuum (Csicsvari et al., 1999). On the basis of the present obser- 
vations, we suggest that at least some of the task-related topographic changes of neuronal activity in the Hampson et al. (1999) study may reflect state-dependent differential contribution of afferent activity.

The present results do suggest a functional segregation of CA1 pyramidal neurons (Eichenbaum et al., 1989). However, this segregation was evident mostly in non-theta state, when the main excitatory drive to the hippocampus arrives from the CA3 region (Buzsáki et al., 1983; Csicsvari et al., 2000). Such local clustering may emerge because during sharp waves selective subgroups of CA3 pyramidal cells discharge together preferentially and consistently (Wilson and McNaughton, 1994; Kudrimoti et al., 1999; Nadasdy et al., 1999; Csicsvari et al., 2000). Given the spatially broad but nevertheless strictly organized projection of CA3 pyramidal cells (Ishizuka et al., 1990; Li et al., 1994), neighboring CA1 pyramidal neurons may discharge together. In contrast, during theta-associated behaviors, the CA3 drive is considerably weaker, and now the convergence of the direct entorhinal input and the trisynaptic granule cell-CA3-CA1 pyramidal cell pathway may be critical for threshold level depolarization of CA1 pyramidal cells (Buzsáki et al., 1995; Hasselmo et al. 2000). The convergence of the monosynaptic and multisynaptic pathways is expected to give rise to considerably larger functional variability than that observed during sharp wave events.

\section{REFERENCES}

Amaral DG, Witter MP (1989) The three-dimensional organization of the hippocampal formation: a review of anatomical data. Neuroscience 31:571-591.

Bland BH (1986) The physiology and pharmacology of hippocampal formation theta rhythms. Prog Neurobiol 26:1-54.

Buzsáki G, Leung LW, Vanderwolf CH (1983) Cellular bases of hippocampal EEG in the behaving rat. Brain Res 287:139-171.

Buzsáki G, Horvath Z, Urioste R, Hetke J, Wise K (1992) Highfrequency network oscillation in the hippocampus. Science 256:1025-1057.

Buzsáki G, Penttonen M, Bragin A, Nadasdy Z, Chrobak JJ (1995) Possible physiological role of the perforant path-CA1 projection. Hippocampus 5:141-146.

Chrobak JJ, Buzsáki G (1996) High-frequency oscillations in the output networks of the hippocampal-entorhinal axis of the freely behaving rat. J Neurosci 16:3056-3066.

Csicsvari J, Hirase H, Czurkó A, Buzsáki G (1998) Reliability and state dependence of pyramidal cell-interneuron synapses in the hippocampus: an ensemble approach in the behaving rat. Neuron 21:179-189.

Csicsvari J, Hirase H, Czurkó A, Mamiya A, Buzsáki G (1999) Oscillatory coupling of hippocampal pyramidal cells and interneurons in the behaving Rat. J Neurosci 19:274-287.

Csicsvari J, Hirase H, Mamiya A, Buzsáki G (2000) Ensemble patterns of hippocampal CA3-CA1 neurons during sharp wave-associated population events. Neuron 28:585-594.

Czurkó A, Hirase H, Csicsvari J, Buzsáki G (1999) Sustained activation of hippocampal pyramidal cells by "space clamping" in a running wheel. Eur J Neurosci 11:344-352.
Eichenbaum H, Wiener SI, Shapiro ML, Cohen NJ (1989) The organization of spatial coding in the hippocampus: a study of neural ensemble activity. J Neurosci 9:2764-2475.

Hampson RE, Byrd DR, Konstantopoulos JK, Bunn T, Deadwyler SA (1996) Hippocampal place fields: relationship between degree of field overlap and cross-correlations within ensembles of hippocampal neurons. Hippocampus 6:281-293.

Hampson RE, Simeral JD, Deadwyler SA (1999) Distribution of spatial and nonspatial information in dorsal hippocampus. Nature 402:610-614

Hasselmo ME, Fransen E, Dickson C, Alonso AA (2000) Computational modeling of entorhinal cortex. Ann NY Acad Sci 911:418-446.

Henze DA, Borhegyi Z, Csicsvari J, Mamiya A, Harris KD, Buzsáki G (2000) Intracellular features predicted by extracellular recordings in the hippocampus in vivo. J Neurophysiol 84:390-400.

Ishizuka N, Weber J, Amaral DG (1990) Organization of intrahippocampal projections originating from CA3 pyramidal cells in the rat. J Comp Neurol 295:580-623.

Kudrimoti HS, Barnes CA, McNaughton BL (1999) Reactivation of hippocampal cell assemblies: effects of behavioral state, experience, and EEG dynamics. J Neurosci 19:4090-4101.

Li XG, Somogyi P, Ylinen A, Buzsáki G (1994) The hippocampal CA3 network: an in vivo intracellular labeling study. J Comp Neurol 339:181-208

Marshall L, Henze DA, Buzsáki G (2000) Spike transmission between hippocampal pyramidal-interneuron pairs is reliable in vivo. Soc Neurosci Abstr 26:187.

Miles R (1990) Synaptic excitation of inhibitory cells by single CA3 hippocampal pyramidal cells of the guinea-pig in vitro. J Physiol (Lond) 428:61-77.

Muller RU, Kubie JL, Ranck Jr JB (1987) Spatial firing patterns of hippocampal complex-spike cells in a fixed environment. J Neurosci 7:1935-1950.

Nadasdy Z, Hirase H, Czurkó A, Csicsvari J, Buzsáki G (1999) Replay and time compression of recurring spike sequences in the hippocampus. J Neurosci 19:9497-9507.

O'Keefe J, Nadel L (1978) Hippocampus as a cognitive map. Oxford, UK: Clarendon.

Redish AD, Battaglia FP, Ekstrom AD, Gerrard JL, Lipa P, Rosenzweig ES, McNaughton BL, Barnes CA (2000) Hippocampal pyramidal cells located near each other anatomically do not show related spatial firing correlates. Soc Neurosci Abstr 26:188.

Stewart M, Fox SE (1990) Do septal neurons pace the hippocampal theta rhythm? Trends Neurosci 13:163-168.

Tamamaki N, Nojyo Y (1995) Preservation of topography in the connections between the subiculum, field CA1, and the entorhinal cortex in rats. J Comp Neurol 353:379-390.

Thompson RF (1986) The neurobiology of learning and memory. Science 233:941-947.

Vanderwolf CH (1969) Hippocampal electrical activity and voluntary movement in the rat. Electroencephalogr Clin Neurophysiol 26:407-418.

Verheugen JA, Fricker D, Miles R (1999) Noninvasive measurements of the membrane potential and GABAergic action in hippocampal interneurons. J Neurosci 19:2546-2555.

Wilson MA, McNaughton BL (1993) Dynamics of the hippocampal ensemble code for space. Science 261:1055-1058.

Wilson MA, McNaughton BL (1994) Reactivation of hippocampal ensemble memories during sleep. Science 265:676-679.

Ylinen A, Bragin A, Nadasdy Z, Jando G, Szabo I, Sik A, Buzsáki G (1995) Sharp wave-associated high-frequency oscillation $(200 \mathrm{~Hz})$ in the intact hippocampus: network and intracellular mechanisms. J Neurosci 15:30-46. 